\title{
David Oliver: Don't blame GPs for late cancer diagnoses
}

\author{
David Oliver
}

Berkshire

Being a GP isn't easy. Under-resourcing, workforce gaps, the rising complexity and volume of work, and a media narrative too often laden with blame add to the challenges. On 28 June the Daily Telegraph ran a column entitled, "GPs failing to spot two thirds of cancers." The article was more measured than the headline. But readers' fear and anger are rarely tempered by less conspicuous details.

It reported a Cancer Research UK study, which had focused on two common cancers (lung and bowel), analysing 135000 cases. ${ }^{2}$ The Telegraph mentioned "average waits of more than eight weeks for diagnosis," adding that "the vast majority of cases that turned out to be cancer were never suspected by family doctors."

The study, based on data from 2014-15, had concluded that only $37 \%$ of all cancers had been diagnosed after urgent referral by a GP suspecting or wanting to rule out the disease. This was true in $32 \%$ of bowel cancer cases and $28 \%$ of lung cancer cases. Patients who had not been referred for urgent assessment waited weeks longer for diagnosis. And 35\% of lung cancer cases and $28 \%$ of bowel cancer cases were diagnosed only when patients presented to hospitals as an emergency.

GPs see a whole range of conditions, often in early stages with undifferentiated symptoms that could easily be many things other than newly presenting cancer. The 2015 NICE guidelines on recognising and referring suspected cancer lowered the positive predictive value threshold for referring cases from 5\% to $3 \%$. ${ }^{3}$ Cancer Research's Cancer in the UK 2019 report showed that, even in 2015-16, only $19 \%$ of cancers were diagnosed as emergencies (and only $6 \%$ through screening programmes)—so most were in fact diagnosed through GP assessment and referral. ${ }^{4}$

The data on Public Health England's bespoke GP profiles illustrate that cancer still represents only a small percentage of a GP's overall caseload. ${ }^{5}$ And some patients, with vague symptoms of cancer not specific to any one organ, risk being sent urgently down the wrong specialist route.

Patients' own circumstances or care preferences also play a part in delayed diagnosis. A study by Abel and colleagues on 4647
NHS patients with a cancer diagnosis from presenting as an emergency found that $29 \%$ reported no prior GP consultation. Percentages were substantially higher in older, male, and deprived patients. ${ }^{6}$

Also consider that, if more patients were referred as urgent cases, our hospital services in radiology, specialty medicine, oncology, and surgery, which already have their own major workforce and workload challenges, would struggle to cope. Indeed, they're already struggling, not least in balancing patients with suspected cancer against those with equally pressing clinical (if not target) priorities.

A Nuffield Trust analysis ${ }^{7}$ of performance against cancer waiting time targets showed that, since measurement started in 2009, we've generally maintained the operational standard of at least $94 \%$ of patients who are referred by GPs as "urgent" being seen within two weeks, with only a recent dip in performance. However, it also showed that the metric of at least $85 \%$ of such patients starting treatment within six weeks of referral has been breached for the past four years and has recently declined further. NHS England's clinical review of national access standards is ongoing, ${ }^{8}$ partly in response to such issues.

Cancer Research UK has a fantastic track record of raising awareness, in line with its charitable mission. It's just a shame that, in this case, the resulting media narrative placed excessive blame on GPs, using old data. I'm not sure that this helps patients or doctors.

Competing interests: See www.bmj.com/about-bmj/freelance-contributors. Provenance and peer review: Commissioned; not externally peer reviewed.

1 Donnelly L. Revealed: GPs failing to spot two thirds of cancers. Telegraph 2019 Jun 28. https://www.telegraph.co.uk/news/2019/06/28/revealed-gps-failing-spot-two-thirds-cancers/

2 Pearson C, Fraser J, Peake M, etal . Establishing population-based surveillance of diagnostic timeliness using linked cancer registry and administrative data for patients with colorectal and lung cancer. Cancer Epidemiol 2019;61:111-8. https://bit.ly/2JrzdKN. 10.1016/j.canep.2019.05.010 31207483

3 National Institute for Health and Care Excellence. Suspected cancer: recognition and referral (NICE guideline NG12). Jun 2015. https:/www.nice.org.uk/guidance/ng12/chapter/ Introduction. 
4 Cancer Research UK. Cancer in the UK 2019. Apr 2019. https://www.cancerresearchuk. org/sites/default/files/state_of_the_nation_april_2019.pdf.

5 Public Health England. Cancer services. https://fingertips.phe.org.uk/profile/cancerservices/ data\#page/ 0 .

6 Abel GA, Mendonca SC, McPhail S, Zhou Y, Elliss-Brookes L, Lyratzopoulos G. Emergency diagnosis of cancer and previous general practice consultations: insights from linked patient survey data. Br J Gen Pract 2017;67:e377-87. 10.3399/bjgp17X690869. https:// bjgp.org/content/67/659/e377. 28438775
7 Nuffield Trust. Cancer waiting times. 28 Mar 2019. https://www.nuffieldtrust.org.uk/resource/ cancer-waiting-time-targets.

8 NHS England. Clinical review of NHS access standards. https://www.england.nhs.uk/ clinically-led-review-nhs-access-standards/.

Published by the BMJ Publishing Group Limited. For permission to use (where not already granted under a licence) please go to http://group.bmj.com/group/rights-licensing/ permissions 